\title{
A Conceptual Framework for Crop-Based Agri-food Supply Chain Characterization Under Uncertainty
}

\author{
M. M. E. Alemany, Ana Esteso, A. Ortiz, J. E. Hernández, A. Fernández, \\ A. Garrido, J. Martín, S. Liu, G. Zhao, C. Guyon, and R. Iannacone
}

\begin{abstract}
Crop-based Agri-food Supply Chains (AFSCs) are complex systems that face multiple sources of uncertainty that can cause a significant imbalance between supply and demand in terms of product varieties, quantities, qualities, customer
\end{abstract}

M. M. E. Alemany $(\bowtie) \cdot$ A. Esteso $\cdot$ A. Ortiz

Universitat Politècnica de València, Camino de Vera s/n, 46022 Valencia, Spain

e-mail: mareva@omp.upv.es

A. Esteso

e-mail: aneslva@doctor.upv.es

A. Ortiz

e-mail: aortiz@upv.es

J. E. Hernández

University of Liverpool Management School, Liverpool, UK

e-mail: J.E.Hernandez@liverpool.ac.uk

A. Fernández $\cdot$ A. Garrido $\cdot$ J. Martín

LIFIA, Facultad de Informática, Universidad Nacional de La Plata, 50 y $115 \mathrm{~s} / \mathrm{n}$,

1900 La Plata, Argentina

e-mail: alejandro.fernandez@lifia.info.unlp

A. Garrido

e-mail: garrido@lifia.info.unlp.edu.ar

J. Martín

e-mail: jonathan.martin@lifia.info.unlp.edu

A. Garrido

CONICET, Buenos Aires, Argentina

S. Liu · G. Zhao

Plymouth Business School, University of Plymouth, Drake Circus, Plymouth PL4 8AA, UK

e-mail: shaofeng.liu@ plymouth.ac.uk

G. Zhao

e-mail: guoqing.zhao@plymouth.ac.uk

C. Guyon

Bretagne Development Innovation, 1bis Route de Fougères, 35510 Cesson-Sévigné, France

e-mail: c.guyon@bdi.fr

(C) The Editor(s) (if applicable) and The Author(s), under exclusive license 
requirements, times and prices, all of which greatly complicate their management. Poor management of these sources of uncertainty in these AFSCs can have negative impact on quality, safety, and sustainability by reducing the logistic efficiency and increasing the waste. Therefore, it becomes crucial to develop models in order to deal with the key sources of uncertainty. For this purpose, it is necessary to precisely understand and define the problem under study. Even, the characterisation process of this domains is also a difficult and time-consuming task, especially when the right directions and standards are not in place. In this chapter, a Conceptual Framework is proposed that systematically collects those aspects that are relevant for an adequate crop-based AFSC management under uncertainty.

Keywords Crop-based agri-food supply chain · Conceptual framework · Uncertainty $\cdot$ Management

\section{Introduction}

The term "agri-food supply chain" (AFSC) has been defined as a set of activities necessary to bring agricultural products "from farm to fork" [1-8]. Thus, AFSCs are responsible for the production and distribution of both vegetable and animal-based products [9]. The production processes of meat and horticulture sectors are very different. For this reason, different frameworks are needed for characterizing them. Since horticulture sector (crop-based AFSCs) has received the least attention in the literature, this chapter will center the research on it.

Crop-based AFSCs are complex systems that face multiple sources of uncertainty that can cause a significant imbalance between supply and demand. Poor management of these sources of uncertainty can have negative impact on quality, safety, sustainability and logistic efficiency of the products and processes as well as in the waste. Thus, a mandatory previous step to develop any decision support tool, especially for the management of every supply chain, is to define the problem under study very precisely, i.e. in a structured way and in a natural language understandable for every crop-based AFSCs implied stakeholder.

The characterisation process of this domains becomes a difficult and very timeconsuming task, especially when standards are not in place. Along these lines, the main objective of this paper is to identify the relevant and distinguishing characteristics of crop-based AFSCs and their sources of uncertainties as a first step in the proper management of different SC processes with the support of different technologies. This is a necessity that arises in the context of the European Project RUC-APS 691249 [10] where, before developing any solution, it was necessary to achieve an understanding between academics and non-academics in order to define agilely

\section{R. Iannacone}

Agenzia Lucana di Sviluppo e di Innovazione in Agricoltura, Centro Ricerche Metapontum Agrobios, Metaponto di Bernalda (MT), Bernalda, Italy

e-mail: rina.iannacone@alsia.it 
the problem to be solved. Conceptual Frameworks have proven their utility and usability for addressing this challenge. Miles and Huberman [11] define a Conceptual Framework as a visual or written product that explains in a graphical or literary way the elements to be studied, the key factors, the concepts or variables and their relationships.

In this paper, a novel Conceptual Framework is proposed that systematically collects relevant aspects for the proper management of crop-based AFSC in an uncertain context based on five views of the system (Physical, Functional, Organization, Informational and Decisional) that, to the best of our knowledge, have not been previously considered in an integrated way. This Conceptual Framework offers several advantages. Firstly, the Conceptual Framework constitutes a tool for the understanding among academics and non-academics in order to precisely define the problem under study. Secondly, it could be used as a reference model for the subsequent development of particular models to support crop-based AFSCs decisionmaking under uncertainty. Thirdly, the Conceptual Framework could be used to review existing approaches in the literature in a structured way. This can help practitioners when searching already existing solutions and can support researchers for identifying gaps in the topic.

The rest of the paper is structured as follows. First, the main blocks to be integrated in the Conceptual Framework are presented. Then, different sections are dedicated to each block, containing detailed description of the constituent elements. Finally, some conclusions are outlined.

\section{Conceptual Framework}

The Conceptual Framework proposed in this paper is structured in different views (Fig. 1), similarly to that proposed by Alemany et al. [12] but with differences regarding the elements of each view and its content.

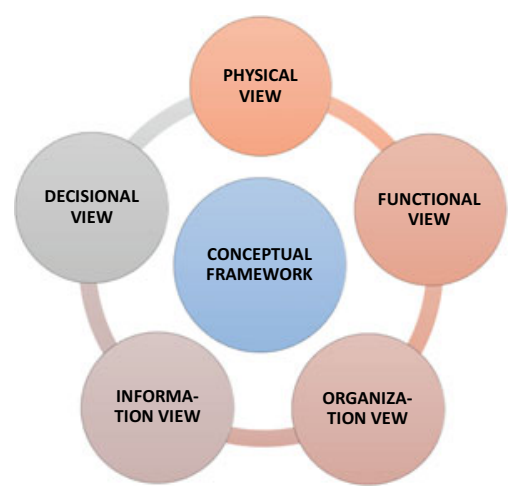

Fig. 1 Views integrated in the conceptual framework for crop-based AFSC 
We assume that crop-based AFSCs decisions (Decisional View) are made on elements such as items and physical and human resources (Physical View), which are specifically arranged (Organisation View), and that particular information (Information View) is required to properly make decisions. The elements of each View and their relationships are described below.

\section{Physical View}

The definition of the problem requires to delimit the physical scope under study, that is, the part of the AFSC that is under our influence as well as their characteristics. The Physical View identifies how a specific supply chain is configured (designed) taking into account its nodes, resources and products including their flows through the supply chain.

\subsection{Products}

One of the main differentiating aspects of crop-based AFSC is the intrinsic characteristics of their products. Based on them, different classification of products can be found in crop-based AFSC literature. Van der Vorst et al. [9] and Teimoury et al. [13] differentiate between products which are going to be directly consumed and products which are going to be processed before being consumed. The formers are also classified, in turn, in perishable and non-perishable products [14]. Differently, Zhang and Wilhelm [15] state that agricultural products may be classified as field crops (e.g., corn, cotton, rice, seeds and wheat) or specialty crops (fruits, vegetables, grapes and wine, ornamentals, tree nuts, berries and dried fruits).

On the other hand, Grillo et al. [16] identify the AFSCs as one of the Lack of Homogeneity in the Product sectors. Lack of Homogeneity in the Product is characterized by the heterogeneity of the products in some attributes that are relevant to the customers. In order to meet with customer homogeneity requirements, these SCs include sorting stages to classify products into homogeneous subtypes based on certain attributes. They identify the following Lack of Homogeneity in the Product characteristics also valid for crop-based AFSCs: Subtype, Subtype Quantity, Subtype Value and Subtype State. These Lack of Homogeneity in the Product features are used to characterize the crops for our Conceptual Framework proposal (Fig. 2).

\subsubsection{Subtype Number}

Subtypes are units of the same crop with the same characteristics requested by the customer. The classification of horticulture products into subtypes depends on the defined attributes to sort products and their possible values. For instance, Blanco et al. 


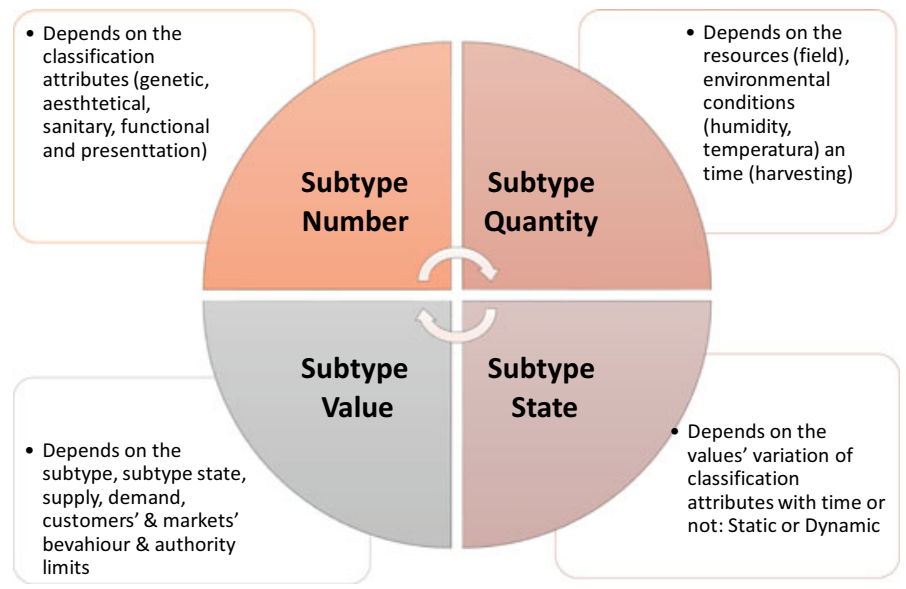

Fig. 2 Products' characteristics of crop-based AFSC

[17] state that during the production process there are different classification stages that provide with a large quantity of final products based on the specific combination of variety, quality, weight, size and packaging. Grillo et al. [18] define subtypes of tarongines based on variety, quality, calibre, packaging type, and harvesting time. Verdouw et al. [19] identify the main criteria for the selection and classification of fruit: the size, weight, maturity, damage, deterioration, color, shape and ripeness.

Therefore, the sorting attributes of crops can be considered genetic (varieties), sanitary (fungi), aesthetic (damages, color, caliber, etc.), functional (sugar content related to taste, freshness) and based on presentation (packaging type). The specific sorting attributes and their potential values will depend on the specific crop provided. Finally, the possible combination of the values of a variety of attributes will provide the AFSC with the number of existing subtypes, which is usually variable and uncertain.

\subsubsection{Subtype Quantity}

Although the final quantity obtained of each subtype may depend on the lot size, its proportion is usually variable. Verdouw et al. [19] states that there is a variation of the quality and, therefore, an appearance of subtypes, between different producers, different production lots and even in the same lot. These factors can depend on the resource (field), the moment of time (harvesting time) and the environmental conditions (temperature and humidity) that increase the diversity and the appearance of subtypes due to the perishable nature of the products. The input-output relationship between the amount of input to a classification stage and the classified output, can be estimated based on historical percentages, but it can be said that it is variable and uncertain. 


\subsubsection{Subtype State}

The value of the attributes of a specific product can be dynamic, if they change over time, or static, if they remain stable. The dynamic subtype state that is closely related to the perishability aspect is one of the crop-based AFSCs particularities. Thus, it is not surprising that most common product classification in these supply chains distinguishes between perishable and non-perishable products [3, 13]. Perishable products have a very limited shelf life which can be measured in days. In contrast, non-perishable products are those which, while having a limited shelf life, can be stored for longer periods of times [3].

The shelf life is defined as the period of time in which the product ceases to have value for the client and usually depends on the environmental conditions. During the shelf-life of a product its attributes can or not deteriorate. The perishable aspect of fresh products implies a variation of their quality with the passage of time [20]. Therefore, it can be said that the state of the subtype is dynamic. Nahmias [21] establishes a classification of perishable food into two categories depending on shelf life:

- Fixed shelf life: the shelf life of the item is predetermined and once it has elapsed, the item becomes worthless: e.g., salads prepared ready-to-eat. When the shelf life is fixed, the most common visual clue is "preferentially consume before" (best-before-date). In this case, customers adapt the price they are willing to pay based on how far the best-before-date is.

- Random life: there is no pre-established length for the shelf life of these items. Their length is random and the probability distribution can take several forms (e.g. vegetables). In this case, the expiration date is not printed and there is a loss of useful lifetime, customers must rely on their external senses or sources of information to estimate the remaining useful life of a product.

\subsubsection{Subtype Value}

It refers to the economic value or utility given by the customer to each subtype in a given state. It can be the same or different for each subtype and, if the subtype state is dynamic, its value can change over time. For instance, in the fruit sector there is a clear dependence between price and quality [22]. Another factor that affects the price of fruit is the supply in relation to the demand. Due to the high fluctuations in the supply of crops, the agricultural sector usually perceives the price of fruit in the open market as random [23]. The supply and demand of vegetables and fruits is seasonal, and the market prices are not known in advance. For this reason, some products can be stored on the farm and sold when prices are higher [24]. Therefore, it can be said that the subtype value is uncertain and dependent on the subtype, the subtype state, the supply, the demand and the customers' and markets' preferences, which at the same time are greatly influenced by the environmental factors. 


\subsection{Resources}

The resources used by the crop-based AFSCs include: fertilizers, pests, land, water, energy, machines and labour, storage and manufacturing facilities and transport means. The proper use of these resources largely impacts on ensuring sustainability: i.e. meeting current needs by using the provided resources in a way that the future generation's ability to satisfy their requirements is not compromised [25]. Kummu et al. [26] made a study about global food supply losses and how this affects the use of resources, such as freshwater, cropland, and fertilisers. They found that the food supply losses consume one quarter of these resources, and that half of them could be saved with proper planning, i.e., applying the minimum loss and waste percentages in each AFSCs step. Their findings highlight the large potential of efficient planning in AFSCs to save natural and scarce resources like freshwater.

\subsection{Supply Chain Configuration}

The SC configuration requires the definition at the Macro-Physical and MicroPhysical level. The first one shows how the network is configured and what material flows through it. Therefore, the elements to be modelled at the MacroPhysical level are: stages, nodes belonging to each stage, type of node (according to the type of activity to be done within the node: production operations, warehousing, selling points, or any combination of these) and arcs, which connect dyadic nodes and represent the flow of items from an origin node to a destination node [12]. Hoekstra and Romme [27] identify six basic types of designs that can be used to describe the relationships between actors: pipeline (one actor), chain (one supplier-one actor one customer), shared resource (several suppliersone actor-several customers), converging (several suppliers-one customer), diverging (one supplier-several customers), and network (several suppliers-several customers) designs. At the Micro-Physical Level, the resources of each node are internally structured (e.g. facility layout and location, process type, etc.) and the composition of the arcs (e.g. transportation modes) that join two different nodes in the network.

\section{Functional View}

Activities that make up crop-based AFSCs have been identified by some authors with different levels of detail. This section first compiles these related works and then presents a proposal for an integrated crop-based AFSC decomposition. Along these lines, Ahumada and Villalobos [3] state that in the context of AFSC there are four main functional areas: production, harvest, storage, and distribution. Kusumastuti et al. [14] complete this definition for the fresh fruit supply chains detailing that there 
is an activity before production called planting/sowing. Others $[4,8]$ set that activities that comprise AFSC are: farming processing/production, testing, packaging, warehousing, transportation, distribution, and marketing.

Both Kusumastuti et al. [14] and Verdouw et al. [19] differentiate between the activities that compose supply chains of fresh products and processed products in fruits supply chains and in AFSC respectively. In the first case [14] the main activities of fresh products AFSC are cultivating, harvesting, pre-processing (activities such as washing and packing the product), storing and transporting. In the second case [19] the main activities of fruit supply chains with fresh products are: growing and harvesting, washing, sorting, grading, packaging, labelling, storage, distribution. Furthermore, Teimoury et al. [13] state that AFSC processed products have an additional activity after pre-processing called processing, where the intrinsic properties of the goods are changed and final products with a higher added value are created to satisfy customer demand. In contrast, Verdouw et al. [19] only recognize that in the case of fruit supply chains processed products, there is a processing activity after growing and harvesting that transforms fresh fruits into food products.

A less detailed proposal is the presented by Borodin et al. [28] where processing of products is also considered by dividing the AFSC activities in: production, storage, processing and distribution. Finally, Handayati et al. [29] have also taken into consideration the processed products of AFSC so they divide the AFSC in: cultivating, harvesting, post-harvest, transporting, processing, marketing, and distributing. Fuertes-Miquel et al. [25] include in their characterization of Brittany Horticulture SC the main activities of breeding new plant varieties, producing seeds and plants, test new varieties and other supporting activities such as test new technologies, training human labor, advising, supporting, coordinating and informing producers and regulate price. On the one hand, in order to extend the products shelf life, some activities where the product is not modified are done before distributing it to customers. Some of the post-harvesting operations are washing, sorting, grading, packaging and labelling [19]. On the other hand, for processed products, preprocessing consists in the preparation of vegetables and fruits to the processing activities. For example, washing a fruit before its processing.

By adapting and integrating the aforementioned authors, Fig. 3 shows a proposal for a decomposition of crop-based AFSC in detailed activities, which also distinguishes between supporting and main activities.

\section{Organization View}

According to Mintzberg [30], organisation structure comprises: (1) the establishment of tasks and (2) co-ordination of those tasks in order to realise objectives. Keuning [31] add (3) the definition of authorities and responsibilities of each task. Therefore, in order to define the Organization View, it is necessary to assign the activities of the Functional View to each actor (stakeholder) and define their relationships. Generally, the following actors can be distinguished in crop-based 


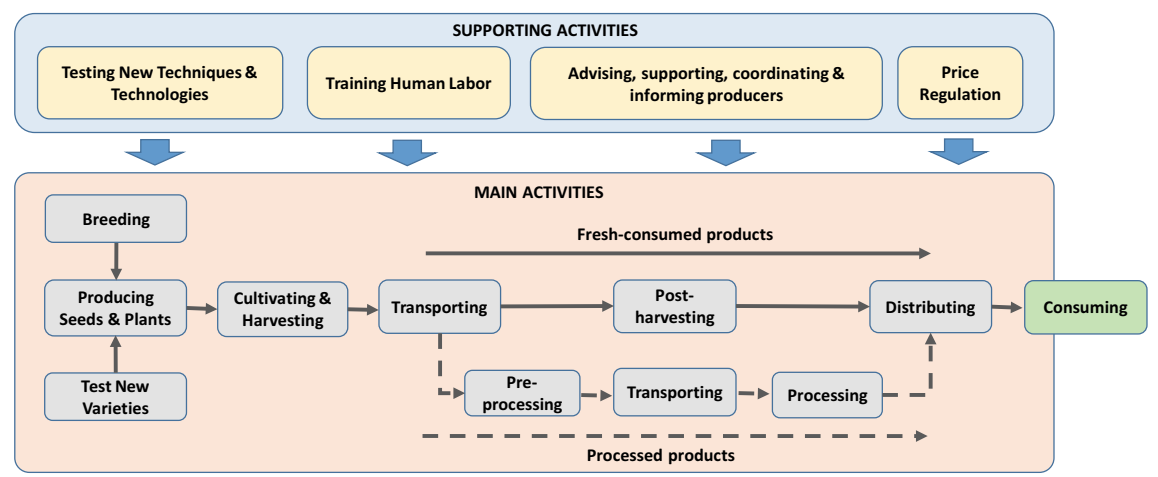

Fig. 3 Crop-based AFSC activities

AFSCs [25]: Research Centers \& Institutes, Experimentation Centers, Training Centers, Growers, Farmers, Manufacture Processors, Cooperatives, Coordinator agents (e.g. Commerce Chamber), Traders (Exporters, Importers), Sorting and Packaging Stations, Consolidators, Auction Markets, Spot Markets, Dispatchers, Wholesalers, Retailers, Government Institutions and Customers. It is worth noting that crop-based AFSCs are traditionally very fragmented with a high number of small farmers and a predominant role of distributors. To properly manage these types of organizations, the level of integration becomes crucial.

\section{Information and Uncertain View}

To successfully execute any decision making-process on crop-based AFSCs it is necessary to get the required information. Decision-making is divided into risky and uncertain situations. In risky situations the decision maker knows both the alternative outcomes and the probability associated with each outcome. Under uncertainty, the decision maker does not know the probability of alternative outcomes [32]. In addition, when making a decision under uncertainty, the decision maker may or may not know the different outcomes that can occur [13].

Different classifications of AFSC uncertainties exist in the literature. Van der Vost [24] classifies generic SC uncertainties in a matrix with four uncertainty types (supply uncertainty, demand and distribution uncertainty, process uncertainty and planning and control uncertainty) affecting three aspects (quality, quantity and time aspects). Backus et al. [33] identify the following five uncertainties in the external environment: natural, technological, social, economic, and polítical factors. Grillo et al. [18] structures inherent lack of homogeneity in the product SC uncertainties in a matrix form with four uncertainty types such as: number of subtypes, subtype quantity, subtype state and subtype value, which that can appear in the different SC stages (supply, process and demand). On the other hand, Esteso et al. [34] propose 


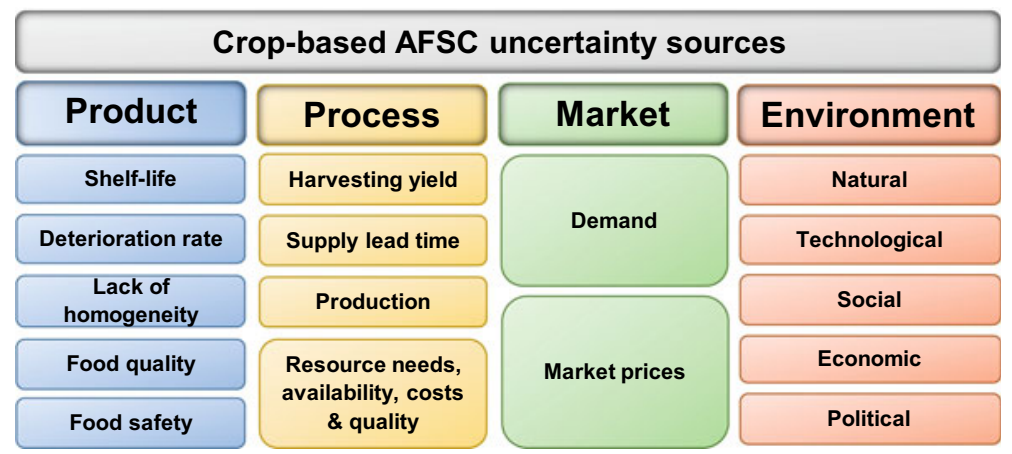

Fig. 4 Crop-based AFSCs uncertainty sources

four types of crop-based uncertainty: Product (shelf-life, deterioration rate, lack of homogeneity, food quality and food safety), Process (harvesting yield, supply lead time, resource needs, production), Market (demand, market prices) and Environment (weather, pests and diseases and regulations). More information on AFSCs under uncertainty can be consulted in Mundi et al. [35] and Grillo et al. [36].

In light of this, the proposed Conceptual Framework aims to classify the uncertainty in AFSCs (Fig. 4) by integrating the aforementioned uncertainties, but also by including others related to resources which, up to our knowledge, have not been identified in the literature yet: cost, availability (e.g., founds and labour) and quality of resources (e.g., land and water).

\section{Decisional View}

The above sources of uncertainties make it very difficult to match supply and demand in terms of customers' requirements of product varieties, qualities, quantities, times and prices. This imbalance, enhanced by the perishability aspect, frequently originates shortage and surplus situations accompanied with a great amount of waste. Poor management of these sources of uncertainties can have negative impact on crop-based AFSC efficiency and customer satisfaction. AFSC management involves a complex and integrated decision-making process that can be characterized by the following elements: Decision Structure (how the decisions are made at different levels and by different stakeholders?), Decisions (which decisions are made?) and Objectives (what are the pursued objectives when finding the value of the decisions to be implemented?). 


\subsection{Decision Structure}

It is composed by the decision levels, the decision-makers at each level and their coordination/integration mechanisms. Three decision levels are usually considered: strategic, tactical and operational corresponding to long, medium and short time horizon, respectively. To achieve the temporal integration between levels, decisions made at higher levels should be respected by lower levels and/or disaggregated in order to be finally implemented on the physical system. Besides, at each temporal level, there can be one decision-maker (centralized decision-making) or several decision-makers (distributed decision-making). For this last case, it is necessary to define the coordination mechanisms among the existing decision-makers with the aim of achieving the spatial integration along the crop-based AFSCs.

\subsection{Decisions}

Several decisions are made at each decision level by specific decision-makers and at different AFSC stages. The most relevant decisions considered by different authors $[3,8,15,37]$ can be consulted in Fig. 5. It is important to highlight that depending on the Customer Order Decoupling Point location, decisions will be made based on demand forecasts (upstream the Customer Order Decoupling Point location) or on customer orders (downstream the Customer Order Decoupling Point location).

\begin{tabular}{|lc|}
\hline \multicolumn{2}{|c|}{ DECISIONS } \\
\hline \multicolumn{2}{|c|}{ STRATEGIC } \\
\hline Crop rotation strategies & Design of supply networks \\
Equipment selection & Financial planning \\
Capacity & Fostering SC partnering relationships \\
Evaluation of perennial crops & Establishing a performance measurement \\
Reservoir management & system \\
Technology selection & Ensuring sustainability \\
CODP Location & Adoption of quality management policies \\
\hline & TACTICAL \\
\hline Crop allocation & Labour scheduling \\
Participation on government & Financial decisions \\
programs & Post-harvesting decisions \\
Drilling policy & Crop selection \\
Water allocation & Supporting food safety via transparency \\
Scheduling of tillage & and traceability \\
Labour capacity & Planning of logistics operations \\
\hline & OPERATIVE \\
\hline Equipment scheduling & Harvesting scheduling \\
Water allocation & Scheduling of production activities \\
Land preparation & Transportation planning \\
Packing planning & Storing \\
\hline
\end{tabular}

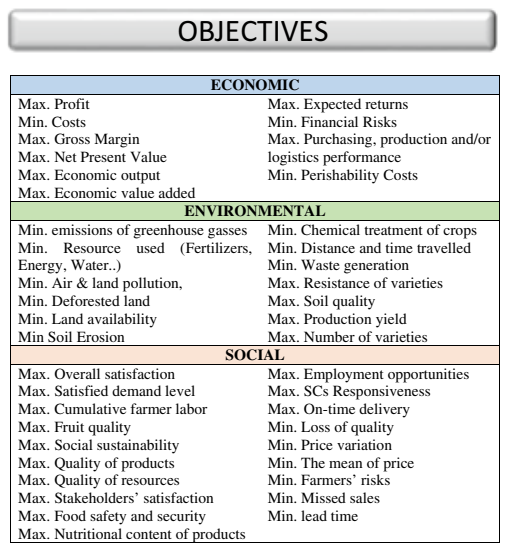

Fig. 5 Main crop-based AFSCs decisions and objectives 


\subsection{Objectives}

The best value of the decisions will depend of the pursed objectives. Different types of SCs are defined based on their objectives. Farahani et al. [38] consider that a $\mathrm{SC}$ is "sustainable" when it considers in their objectives economic, environmental and social aspects. However, it is called "green" if it considers environmental and economic aspects, and is known as a "lean" when it considers only the economical aspect. Figure 5 shows the most common objectives of each type for crop-based AFSCs [25, 39-41]. Some of these objectives can be conflicting, being important to develop multi-objective or multi-criteria decision-making models.

\section{Conclusions}

The crop-based AFSCs operation has a significant impact on social, environment and economical aspects. However, the management of these supply chains becomes very complex due to their inherent products' characteristics, their sources of uncertainty and their fragmented organizational and decisional structure. Therefore, when making decisions at a specific temporal level (strategic, tactical or operational) for a specific AFSC process, it is necessary to gather the relevant aspects that will impact on the decisions to be made. Due to the inherent complexity of AFSC, this is not a trivial task.

In this paper, we propose a Conceptual Framework as a tool for gathering this information in a structured way by means five different views: physical, functional, organization, information and decisional under uncertainty. Indeed, the Conceptual Framework can be understood as a reference model (i.e. an abstract and general model) of any AFSCs. The Conceptual Framework when particularized to a specific AFSC will allow a structure description of its elements and their relationships under uncertainty, improving the understanding of the AFSC as a whole in order to make better decisions. For instance, the Conceptual Framework particularization of the physical view will make clearer which resources (plants, suppliers, transportation vehicles) of the AFSC are inside the scope of our decisions, which products flow along them and which of their characteristics are relevant to take into account. The particularization of the decisional view for a specific decisional process, support the decision-makers to guide the decisions to be considered and the objectives to be pursued in order to be sustainable.

The proper characterization of any AFSCs is required as a preceding step to develop reliable models to support its decision-making processes at the strategic, tactical and operational level under uncertainty. However, our proposal does not provide a direct relationship between the conceptual framework and the decisional models. For this, a more detailed methodology should be developed. The Conceptual Framework is a valuable tool for communication among decision-maker and/or 
researchers and AFSC stakeholders. Finally, it can be used to define the structural dimensions to analyse the literature on a specific decision-making process, identifying existing works and gaps for future research.

Acknowledgement Authors of this publication acknowledge the contribution of the Project 691249, RUC-APS "Enhancing and implementing Knowledge based ICT solutions within high Risk and Uncertain Conditions for Agriculture Production Systems" (www.ruc-aps.eu), funded by the European Union under their funding scheme H2020-MSCA-RISE-2015.

\section{References}

1. Taylor, D.H., Fearne, A.: Towards a framework for improvement in the management of demand in agri-food supply chains. Supply Chain Manage. 11, 379-384 (2006)

2. Matopoulos, A., Vlachopoulou, M., Manthou, V., Manos, B.: A conceptual framework for supply chain collaboration: empirical evidence from the agri-food industry. Supply Chain Manage. 12, 177-186 (2007)

3. Ahumada, O., Villalobos, J.R.: Application of planning models in the agri-food supply chain: a review. Eur. J. Oper. Res. 196, 1-20 (2009)

4. Iakovou, E., Vlachos, D., Achillas, C., Anastasiadis, F.: A methodological framework for the design of green supply chains for the agrifood sector. Paper presented at the 2 nd international conference on supply chains, Katerini, 5-7 Oct 2012

5. Manzini, R., Accorsi, R.: The new conceptual framework for food supply chain assessment. J. Food Eng. 115, 251-263 (2013)

6. Shukla, M., Jharkharia, S.: Agri-fresh produce supply chain management: a state-of-the-art literature review. Int. J. Oper. Prod. Manage. 33, 114-158 (2013)

7. Lemma, Y., Kitaw, D., Gatew, G.: Loss in perishable food supply chain: an optimization approach literature review. Int. J. Sci. Eng. Res. 5, 302-311 (2014)

8. Tsolakis, N.K., Keramydas, C.A., Toka, A.K., Aidonis, D.A., Iakovou, E.T.: Agrifood supply chain management: a comprehensive hierarchical decision-making framework and a critical taxonomy. Biosyst. Eng. 120, 47-64 (2014)

9. Van der Vorst, J.G., Da Silva, C.A., Trienekens, J.H.: Agro-industrial Supply Chain Management: Concepts and Applications. FAO (2007)

10. Hernandez, J., Mortimer, M., Patelli, E., Liu, S., Drummond, C., Kehr, E., Calabrese, N., Iannacone, R., Kacprzyk, J., Alemany, M.M.E., Gardner, D.: RUC-APS: enhancing and implementing knowledge based ICT solutions within high risk and uncertain conditions for agriculture production systems. In: 11th International Conference on Industrial Engineering and Industrial Management, Valencia, Spain (2017)

11. Miles, M.B., Huberman, A.M.: Qualitative Data Analysis: An Expanded Sourcebook. Sage Publications, Thousand Oaks (1994)

12. Alemany, M.M.E., Alarcón, F., Lario, F.C., Boj, J.J.: An application to support the temporal and spatial distributed decision-making process in supply chain collaborative planning. Comput. Ind. 62, 519-540 (2011)

13. Teimoury, E., Nedaei, H., Ansari, S., Sabbaghi, M.: A multi-objective analysis for import quota policy making in a perishable fruit and vegetable supply chain: a system dynamics approach. Comput. Electron. Agric. 93, 37-45 (2013)

14. Kusumastuti, R.D., van Donk, D.P., Teunter, R.: Crop-related harvesting and processing planning: a review. Int. J. Prod. Econ. 174, 76-92 (2016)

15. Zhang, W., Wilhelm, W.E.: OR/MS decision support models for the specialty crops industry: a literature review. Ann. Oper. Res. 190, 131-148 (2011) 
16. Grillo, H., Alemany, M.M.E., Ortiz, A.: A review of mathematical models for supporting the order promising process under lack of homogeneity in product and other sources of uncertainty. Comput. Ind. Eng. 91, 239-261 (2016)

17. Blanco, A.M., Masini, G., Petracci, N., Bandoni, J.A.: Operations management of a packaging plant in the fruit industry. J. Food Eng. 70, 299-307 (2005)

18. Grillo, H., Alemany, M.M.E., Ortiz, A., Fuertes-Miquel, V.S.: Mathematical modelling of the order-promising process for fruit supply chains considering the perishability and subtypes of products. Appl. Math. Model. 49, 255-278 (2017)

19. Verdouw, C.N., Beulens, A.J.M., Trienekens, J.H., Wolferta, J.: Process modelling in demanddriven supply chains: a reference model for the fruit industry. Comput. Electron. Agric. 73, 174-187 (2010)

20. Amorim, P., Günther, H., Almada-Lobo, B.: Multi-objective integrated production and distribution planning of perishable products. Int. J. Prod. Econ. 138, 89-101 (2012)

21. Nahmias, S.: Perishable inventory theory: a review. Oper. Res. 30, 680-708 (1982)

22. Mowat, A., Collins, R.: Consumer behavior and fruit quality: supply chain management in an emerging industry. Supply Chain Manage. 5, 45-54 (2000)

23. Kazaz, B., Webster, S.: The impact of yield-dependent trading costs on pricing and production planning under supply uncertainty. M\&SOM Manuf. Serv. Oper. Manage. 13, 404-417 (2011)

24. Van der Vorst, J.G.: Effective food supply chains: generating, modelling and evaluating supply chain scenarios (2000)

25. Fuertes-Miquel, V.S., Cuenca, L., Boza, A., Guyon, C., Alemany, M.M.E.: Conceptual framework for the characterization of vegetable breton supply chain sustainability in an uncertain context. In: 12th International Conference on Industrial Engineering and Industrial Management, XXII Congreso de Ingeniería de Organización, Girona, Spain, 12-13 July 2018

26. Kummu, M., de Moel, H., Porkka, M., Siebert, S., Varis, O., Ward, P.J.: Lost food, wasted resources: global food supply chain losses and their impacts on freshwater, cropland, and fertiliser use. Sci. Total Environ. 438, 477-489 (2012)

27. Hoekstra, S., Romme, J.: Integral Logistic Structures: Developing Customer-Oriented Goods Flow. Industrial Press Inc., New York (1992)

28. Borodin, V., Bourtembourg, J., Hnaien, F., Labadie, N.: Handling uncertainty in agricultural supply chain management: a state of the art. Eur. J. Oper. Res. 254, 348-359 (2016)

29. Handayati, Y., Simatupang, T.M., Perdana, T.: Agri-food supply chain coordination: the stateof-the-art and recent developments. Logist. Res. 8, 1-15 (2015)

30. Mintzberg, H.: The Structuring of Organisations. Prentice-Hall, Upper Saddle River (1979)

31. Keuning, D.: Grondslagen Van Het Management. Stenfert Kroese, Houten (1995) (in Dutch)

32. Esteso, A., Alemany, M.M.E., Ortiz, A.: Conceptual framework for designing agri-food supply chains under uncertainty by mathematical programming models. Int. J. Prod. Res. (2018)

33. Backus, G.B.C., Eidman, V.R., Dijkhuizen, A.A.: Farm decision making under risk and uncertainty. Neth. J. Agr. Sci. 45, 307-328 (1997)

34. Esteso, A., Alemany, M.M.E., Ortiz, A.: Conceptual framework for managing uncertainty in a collaborative agri-food supply chain context. In: IFIP Advances in Information and Communication Technology, vol. 506, pp. 715-724 (2017)

35. Mundi, I., Alemany, M.M.E., Poler, R., Fuertes-Miquel, V.S.: Review of mathematical models for production planning under uncertainty due to lack of homogeneity: proposal of a conceptual model. Int. J. Prod. Res. (2019)

36. Grillo, H., Alemany, M.M.E., Ortiz, A., De Baets, B.: Possibilistic compositions and state functions: application to the order promising process for perishables. Int. J. Prod. Res. (2019)

37. Soto-Silva, W.E., Nadal-Roig, E., González-Araya, M.C., Pla-Aragones, L.M.: Operational research models applied to the fresh fruit supply chain. Eur. J. Oper. Res. 251, 345-355 (2016)

38. Farahani, R.Z., Rezapour, S., Drezner, T., Fallah, S.: Competitive supply chain network design: an overview of classifications, models, solution techniques and applications. Omega 45, 92-118 (2014)

39. Banasik, A., Bloemhof-Ruwaard, J.M., Kanellopoulos, A., Claassen, G.D.H., van der Vorst, J.G.: Multi-criteria decision making approaches for green supply chains: a review. Flex. Serv. Manuf. J. 1-31 (2016) 
40. Paam, P., Berretta, R., Heydar, M., Middleton, R.H., García-Flores, R., Juliano, P.: Planning models to optimize the agri-fresh food supply chain for loss minimization: a review. In: Reference Module in Food Science (2016)

41. Soysal, M., Bloemhof-Ruwaard, J.M., Meuwissen, M.P., van der Vorst, J.G.: A review on quantitative models for sustainable food logistics management. Int. J. Food Syst. Dyn. 3, 136-155 (2012) 